\title{
Mathematical Problems Solving Conception (MaProSC) Scale
}

\author{
Dulce E. Catindoy
}

Instructor III, Head, Department of Teacher Education, Visayas State University-Alangalang, Alangalang Leyte, Philippines

Received: 13 Sep 2021; Received in revised form: 16 Oct 2021; Accepted: 22 Oct 2021; Available online: 31 Oct 2021 C2021 The Author(s). Published by Infogain Publication. This is an open access article under the CC BY license (https://creativecommons.org/licenses/by/4.0/).

\begin{abstract}
The problem of the current research is to develop and instrument that will assess students' conception on mathematical problem solving as a process and as to its characteristics as an activity in a classroom setting. A confirmatory factor analysis with Varimax rotation and elimination loadings were used in the validation of the pre-identified constructs which are problem solving as a process and problem solving as to its characteristics. There were 19-items retained in the first factor about students' views on problem solving as a process and 17 items describing on students' perception of mathematical problem solving as to its characteristics. The results of this study also need to be re-examined to determine if they can be replicated with other samples of students as well as adding factors and items that would measure students' conception on mathematical problem solving.
\end{abstract}

Keywords-Problem solving, mathematical knowledge, NCTM.

\section{INTRODUCTION}

Problem solving is a fundamental means of developing mathematical knowledge at any level. As emphasized by the National Council of Mathematics Teachers (NCTM, 1979), "Problem solving means engaging in a task for which the solution method is not known in advance. In order to find a solution, students or problem solver must know on their knowledge, and through this process, they will often develop new mathematical understandings. Solving problems is not only a goal of learning mathematics, but also a major means of doing so." (NCTM, 1978). As also stresses by Lester (2013)\&Schoenfeld (1992), "problem solving is the heart of mathematics". Learning to solve problems is the principal reason for studying mathematics. To become a good problem solver in mathematics, one must develop a base of mathematics knowledge. Silver (1979) found that successful problem solvers were more likely to categorize math problems on the basis of their underlying similarities in mathematical structure. In connection, it is pointed out in the study conducted by Tan \&Limjap (2018) that the first phase students will be able to bear in mind is to understand the problem. But this will be realized if students fully understand what is mathematical problem solving as a process and as to its characteristics.

The NCTM (1989) has strongly endorsed the inclusion of problem solving in school mathematics. There are many reasons for doing this.

"First, problem solving is a major part of mathematics. It is the sum and substance of our discipline and to reduce the discipline to a set of exercises and skills devoid of problem solving is misrepresenting mathematics as a discipline and shortchanging the students. Second, mathematics has many applications and often those applications represent important problems in mathematics. Our subject is used in the work, understanding, and communication within other disciplines. Third, there is an intrinsic motivation embedded in solving mathematics problems. We include problem solving in school mathematics because it can stimulate the interest and enthusiasm of the students. Fourth, problem solving can be fun. Many of us do mathematics problems for recreation. Finally, problem solving must be in the school mathematics curriculum to allow students to develop the art of problem solving." 
The Mathematical Problem Solving Conception Scale (MaProSC) instrument will assess student's conception on mathematical problem solving as a process and as to its characteristics as an activity in a classroom setting. It is important that students will be able to know the importance of problem solving in mathematical thinking because this is very essential in mathematics education (Doorman et.al, 2007). The author of this MaProSC is guided with Scott Chamberlin's article on What is problem solving in the mathematics classroom?In his article, he pointed out on that characteristics and processes may be used to identify true problem solving. But in the current study, set of items were formulated to answer how do students view mathematical problem solving as a process and as to its characteristics.

As a teacher of basic mathematics in tertiary level, it is important to instill in the mind of students on the problem solving with the emphasis not only focusing on the steps how to solve problems but also determining their conceptions about mathematical problem solving.

\section{The Instrument}

The instrument is composed of two sections namely student's conception on mathematical problem solving (PS) as a process and students view of problem solving as to its characteristics in a classroom setting. This is composed of 39 items, 21 - items for PS as a process and 18 - items as to its characteristics. The respondents will respond the questionnaire using Likert scale, 5 (strongly agree) as the highest while 1 (strongly disagree) as the lowest. The purpose of this scale is to assess students' conception on mathematical problem solving as a process and as to its characteristics as an activity in a classroom setting.

\section{METHODOLOGY}

The constructed questionnaire was pilot tested among 117 sample education students in one of the state university in Leyte through personal administration with the help of fellow faculty of the author. Of the complete sample, $91(77.8 \%)$ were female and 26 (22.22\%) were males. Moreover, $50.4 \%$ were Bachelor of Secondary Education-Math (BSEd) students and $49.6 \%$ were from Bachelor of Elementary Education (BEED). From this two courses, there were $54(46.2 \%)$ third year students, $36.8 \%$ came from second year, and $17.1 \%$ were fourthyear students. The author used convenience sampling in choosing the respondents. Letter of consent was written to the Teacher Education Department head and to the respective classes who will answer theMaProSCscale.Pilot testing used the rule of thumb range from 3:1 (Williams, et.al, 2010)
The questionnaire is originally composed of $42-$ items originally formulated by the author based on the definitions of mathematical problem solvingas a process (22 items) and as to its characteristics (20 items). These two constructs (mathematical problems solving as a process and mathematical problems solving as to its characteristics) defined the mathematical problems solving conception (MaProSC) scale.

The researcher consulted three experts for the pretesting of the questionnaire who were at the field of education and experienced teachers in mathematics. Relevance (4 - very relevant and succinct, 3 - relevant but needs revision, 2 - unable to assess relevance, 1 - not relevant) and representativeness( 4 - item is representative, 3 - item needs minor revisions to be representative, 2 item needs major revisions to be representative, 1 - item is not representative) were the basis how do experts score each item. The experts were also requested to recommend revisions that would strengthen the item descriptions of the two constructs. At the end of the pretesting, 39 - items ( 21-items for problem solving as a process; 18-items for problems solving as to its characteristics.Content validity of individual items was computed using Lynn (1986) recommendation. She recommended that with a panel of "five or fewer experts, all must agree on the content validity for their rating to be considered a reasonable representation of the universe of possible ratings" ; in other words, if there are five or fewer judges should be 1.00.

All items were rated on a 5-point Likert scale which ranging from " 1 " as "Strongly Disagree" to " 5 " to "Strongly Agree". Based on the reliability analysis, the Cronbach alpha value of the whole questionnaire is 0.915 which is acceptable since it is above the recommended value (Spector, $1992 \&$ Colton \& Covert, 2007).

\section{RESULT, CONCLUSION AND RECOMMENDATIONS}

During the pretesting, three experts rated each item based on the constructed scale on relevance (4 - very relevant and succinct, 3 - relevant but needs revision, 2 - unable to assess relevance, 1 - not relevant) and representativeness ( 4 - item is representative, 3 - item needs minor revisions to be representative, 2 - item needs major revisions to be representative, 1 - item is not representative). The mean was computed and those items with mean ranges from 3 to 4 were retained while items whose mean were below 3 were deleted. So that two (item 3 and 14) items were deleted on how do students view problem solving as a process while 5-items (items 4,8, 9, 10, and 11) were eliminated on students' view of problem solving as to its characteristics. Some of the retained items were suggested 
by experts to be revised since the author seeks suggestions and recommendations of the items. After the pretesting there were 21-items which were retained on students' view of problem solving as a process and 18-items were retained on problems solving as to its characteristics.

The result of the pre-testing can be gleaned in Table 1 below.

Table 1. Pre-testing Result

\section{Statements
A..As student/problem solver, I successfully complete a mathematical problem solving task if...}

1. I can propose a solution.

2. I can find solution to a mathematical problem through writing an equation.

3. I can transfer ideas to peers.

4. I can create a plan in solving the problem through drawing a picture.

5. I can generate written record of the way/s I think.

6. I can seek multiple solutions.

7. I can make an answer to a mathematical problem with the use of current knowledge.

8. I can mathematically think a situation to solve a problem.

9. I can produce assumptions.

10. I use assumptions in relation to my final solution.

11. I can apply current knowledge to solve a problem.

12. I am always ready for a mathematical challenge.

13. I can create new techniques to solve a problem.

14. I do not implement a pre-learnt process to solve it.

15. I can analyze relevant data in a specific problem

16. I can directly create a potential solution.

17. I can easily identify appropriate formula for the problem.

18. I can identify what are given conditions.

19. I can describe mathematical condition.

20. I can easily pin point unique method to solve problem than others.

21. I can evidently explain the process in given situation.

22. I can solve a problem using tabular representations.

\section{B. .As a student/problem solver, I view mathematical problem} solving activity as...

1. real-life application.

2. requiring reasoning skills.

3. solving with more than one method.

4. finding a way around a difficult situation.

5. innovation of situation for problem solver/s.

3.67

3.67

$\begin{array}{cc}\begin{array}{c}\text { Level of } \\ \text { Representativeness }\end{array} & \begin{array}{c}\text { Level of } \\ \text { Relevance }\end{array}\end{array}$

DECISION
Mean

3.67

3.67

2.67

3.67

3.33

3.33

3.67

3.33

3.33

3.33

3.00

3.67

2.33

4.00

4.00

4.00

3.67

3.33

4.00

4.00

2.33

\section{Mean}

3.67

Retained

3.67

Retained

2.67

Deleted

3.67

Retained

3.33

Retained

3.33

Retained

3.67

Retained

3.33

Retained

3.33

Retained

3.67

Retained

3.67

Retained

3.33

Retained

3.67

2.67

Retained

Delete

4.00

Retained

3.67

Retained

4.00

Retained

4.00

Retained

3.67

Retained

$3.00 \quad$ Retained

4.00

Retained

4.00

Retained
Retained

Retained

3.67

Retained

3.33

Retained

2.33 


\begin{tabular}{lllc}
\hline 6. measurement of level of understanding. & 2.67 & 2.67 & Retained \\
7. a series of processes to arrive a correct solution. & 3.67 & 3.67 & Retained \\
8. demanding mindful responses. & 2.00 & 2.00 & Delete \\
9. flexible way of thinking. & 2.00 & 2.00 & Delete \\
10. applying multiple steps for successful solution. & 2.67 & 2.67 & Delete \\
11. task for solving fixed mathematical problems. & 2.33 & 2.33 & Delete \\
12. solvingpuzzles. & 3.67 & 3.67 & Retained \\
13. playing games by reasoning. & 4.00 & 4.00 & Retained \\
14. application of mathematical concepts & 4.00 & 4.00 & Retained \\
15. development of creative thinking. & 4.00 & 4.00 & Retained \\
16. solving non-routine situations. & 3.00 & 3.33 & Retained \\
17. condition that requires open - ended situation. & 2.67 & 3.00 & Retained \\
18. explanation of accurate mathematical data. & 3.33 & 3.67 & Retained \\
19. requirement of unique mathematical situations. & 3.33 & 2.67 & Retained \\
20. enhancement self-realization. & 3.33 & 3.33 & Retained \\
\hline
\end{tabular}

Using confirmatory factor analysis with Varimax rotation and elimination loadings below o.40, validation of the pre-identified constructs (problem solving as a process and problem solving as to its characteristics) was performed for the 39-items.

After meeting the desired sampling adequacy (Kaiser-Meyer-Olkin $=0.895$ ), the reliability of the MaProSC scale using Cronbach alpha coefficient resulted a reliability coefficient of $0.915(91.5 \%)$. Originally, MaProSC scale has two factors. Using confirmatory factor analysis to validate the two pre-identified constructs of mathematical problems solving conception and eliminate factor loadings $<0.40,36$-items remained in the two factors extraction with an accounted total variance of $49.53 \%$ with reliability coefficient $0.915(91.5 \%)$.

After validation, the two factors consist of the same items from the original questionnaire but with some statements which did not load to the respective factors. First factor, item 15 'I can directly create a potential solution' was the item with highest factor loading (0.736). This statements agrees to Polya's (1980) definition of problem solving as a way where there is no known way around an obstacleas stated in the article What is problem solving ability by Carmen Laterell. In short, finding a way is finding potential solution to solve a mathematical problem solving. Rest of the items which load in this factor with factor loadings greater than 0.40 had to do with students' views of mathematical problems solving as a process. The items that were retained in the first factor were items $1,2,3,4,6,7,8,9,10,11,12,13,14,15,16,17,18,19$ and 20. So that, there were 19-items retained in the first factor about students' views on problem solving as a process. Meanwhile, there were two statements did not load to this first factor. These were item 5 'I can seek multiple solutions' and item 21 'I can solve a problem using tabular representations'. These were excluded in the final composition of the MaProSC scale.

The second factor accounted $49.53 \%$ of the variance and included items describing on students' perception of mathematical problem solving as to its characteristics. Item 7 'application of critical thinking skills' loads with the highest value which is 0.848 . There were seventeen items $(1,2,3,4,5,6,7,8,9,10,11,12,14,15,16,17,18)$ load in the said factor while only one item did not load for this factor. This item 13 which states 'condition that requires openendedness'. This was excluded in the scale. As the result of the study conducted by Prayitno (2018) students must possess critical thinking skills to solve mathematical problem solving.

Therefore, result of this study revealed satisfaction in attaining the purpose of developing a Mathematical Problem Solving Conception Scale questionnaire and of meeting the least desired validity, reliability and practicality of the researcher. Within the acceptable range of validity and reliability, the final version of the instrument can be utilized in attaining the purpose of developing it. Moreover, the clear description of the response category as well as the elimination of some undesirable items determines that the questionnaire can be used to measure mathematical problem solving conception. 
Furthermore, the result of factor analysis which enables the identification of a more inclusive naming of factors would be helpful enough for future users. It would guide mathematics educators assess the level of mathematical problem solving conception of students.

The results of this study also need to be reexamined to determine if they can be replicated with other samples of students as well as adding factors and items that would measure students' conception on mathematical problem solving.

\section{REFERENCES}

[1] National Council of Teachers of Mathematics. (1989). Curriculum and evaluation standards for school mathematics. Reston, VA: The Author

[2] National Council of Supervisors of Mathematics. (1978). Position paper on basic mathematical skills. Mathematics Teacher, 71(2), 147-52. (Reprinted from position paper distributed to members January 1977.)

[3] Prayitno, Anton. 2018. Characteristics of students' critical thinking in solving mathematics problem. The Online Journal of New Horizons in Education

[4] Schoenfeld, A. H. (1985). Mathematical problem solving. Orlando, FL: Academic Press.

[5] Silver, E. A. (1979). Student perceptions of relatedness among mathematical verbal problems. Journal for Research in Mathematics Education, 10(3), 195-210. 